\title{
Development of Film Dosage Form Containing Allopurinol for Prevention and Treatment of Oral Mucositis
}

\author{
Yoshifumi Murata, ${ }^{1}$ Kyoko Kofuji, ${ }^{1}$ Norihisa Nishida, ${ }^{2}$ and Ryosei Kamaguchi ${ }^{2}$ \\ ${ }^{1}$ Faculty of Pharmaceutical Science, Hokuriku University, Ho-3, Kanagawa-machi, Kanazawa 920-1181, Japan \\ ${ }^{2}$ Morishita Jintan Co. Osaka Technocenter, 2-11-1, Tudayamate, Hirakata, Osaka 573-0128, Japan \\ Correspondence should be addressed to Yoshifumi Murata, y-murata@hokuriku-u.ac.jp \\ Received 13 December 2011; Accepted 10 January 2012 \\ Academic Editor: G. Ragno
}

Copyright (C) 2012 Yoshifumi Murata et al. This is an open access article distributed under the Creative Commons Attribution License, which permits unrestricted use, distribution, and reproduction in any medium, provided the original work is properly cited.

Film dosage forms (FDs) containing allopurinol (AP) were prepared using a casting method with water-soluble polysaccharides, such as sodium alginate (ALG), and the release profile of AP from FDs was investigated in limited dissolution medium. Some ALGs were able to form FDs incorporating AP, and the thickness was about $50 \mu \mathrm{m}$. All FDs were easy to handle, though the rheological properties varied with ALG species. AP was homogenously present throughout the FDs and was released with disintegration in $10 \mathrm{~mL}$ of physiological saline. These results confirmed that FDs are useful for preventing or treating localized problems in the oral cavity, such as mucositis. FDs are also useful for administering drugs to cancer patients receiving chemotherapy and/or radiotherapy.

\section{Introduction}

The xanthine oxidase inhibitor allopurinol (AP) is a drug used for the treatment of gout. AP has also been used to prevent and treat oral mucositis (mouth ulcers) in cancer patients receiving chemotherapy and/or radiotherapy [1-3]. In the treatment of mucositis, direct application of AP to the oral mucosa is necessary to avoid the systemic action seen after gastrointestinal absorption as the antioxidant activity of $\mathrm{AP}$ will result in lowering the activity of anticancer drug such as methotrexate. For example, AP suspensions $(1 \mathrm{mg} / \mathrm{mL})$ are freshly prepared in the hospital, and the patient gargles with the preparation [4]. This method for preventing mucositis is simple and effective; however, these preparations are not stable for long-term preservation, and it is difficult to control the amount of AP during gargling, although the dose is not sufficiently high to induce systemic effects in the event of erroneous swallowing.

Recently, oral disintegration (OD) dosage forms such as OD tablets have become widely utilized, as they are useful in patients who have difficulty swallowing regular tablets $[5,6]$. Film dosage forms (FDs) are also anticipated to be useful in oral care [7-9]. The active compound present in FDs is spread in the oral cavity as the form disintegrates on contact with saliva, and the disintegration profile of FDs can be varied by modifying the film base [10]. However, the drug loading capacity of FDs is typically very low, and the drug incorporated into FDs should be selected carefully.

FDs are generally prepared using a water-soluble polymer base for immediate dissolution in saliva. As various polysaccharides have been used as additives for drug preparation or food ingredients because of the safety on peroral administration, they are candidate materials for FD preparation. Algal polysaccharide sodium alginate (ALG) consists of $\alpha$-Lguluronate and $\beta$-D-mannuronate and is able to form thin films $[11,12]$. Pullulan (PUL), a polysaccharide composed of $\alpha$-D-maltotriose, is also a known film base [13]. In this study, we prepared FDs containing AP using a casting method with natural polysaccharides without dissolution in organic solvents, heating, $\mathrm{pH}$ regulation, or addition of plasticizer. The release profiles for AP from FDs were then investigated in limited dissolution medium, as AP is expected to be active following dissolution in saliva upon oral FD administration.

\section{Materials and Methods}

2.1. Materials. Three species of ALG (300 cps, $500 \mathrm{cps,}$ and $1000 \mathrm{cps}$ ) were obtained from the Nacalai Tesque Inc. 


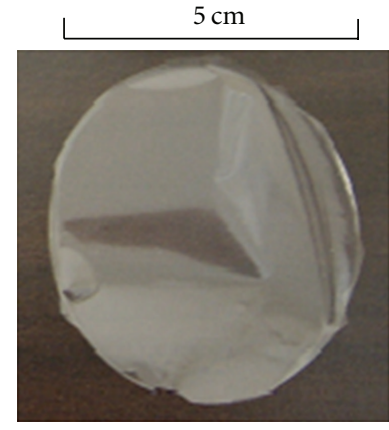

$1.5 \% 300 \mathrm{cps}$

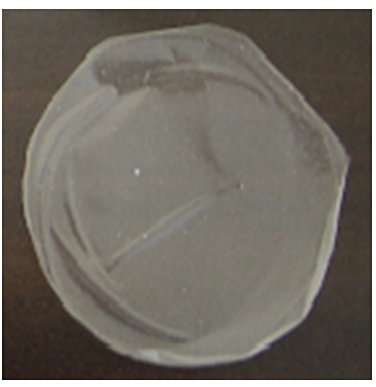

$1.5 \% 300 \mathrm{cps}$ $0.5 \%$ PGA

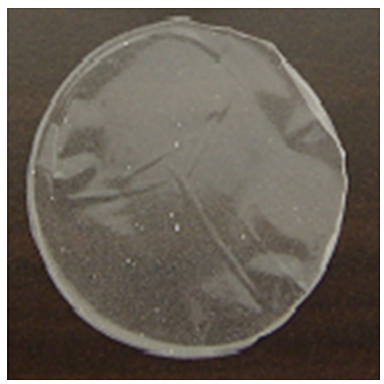

$1.5 \% 500 \mathrm{cps}$

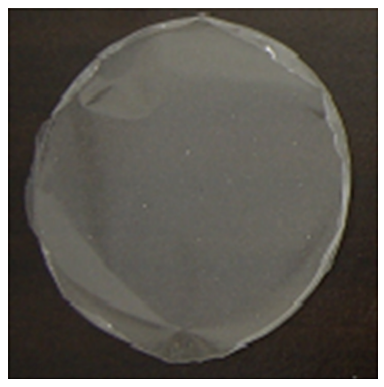

$1.5 \% 500 \mathrm{cps}$ $0.5 \%$ PGA

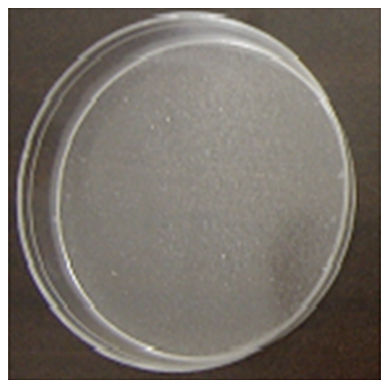

$1.5 \% 1000 \mathrm{cps}$

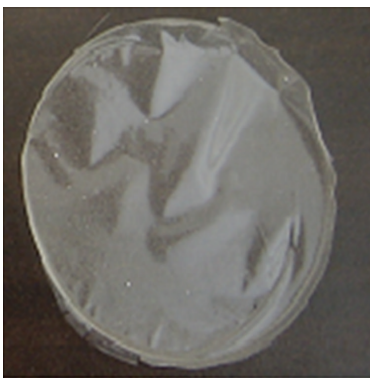

$1.5 \% 1000 \mathrm{cps}$ $0.5 \%$ PGA

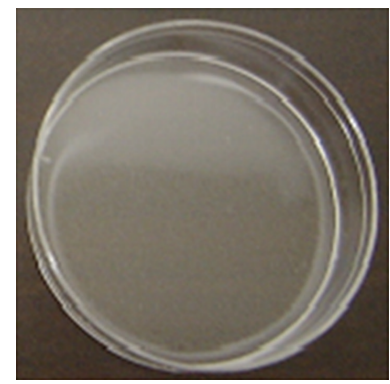

4\% PUL

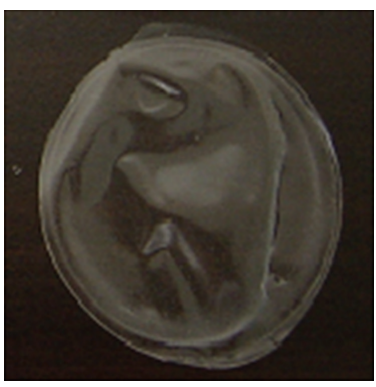

4\% PUL 0.5\% PGA

FIgURE 1: Images of FDs prepared with polysaccharides containing AP.
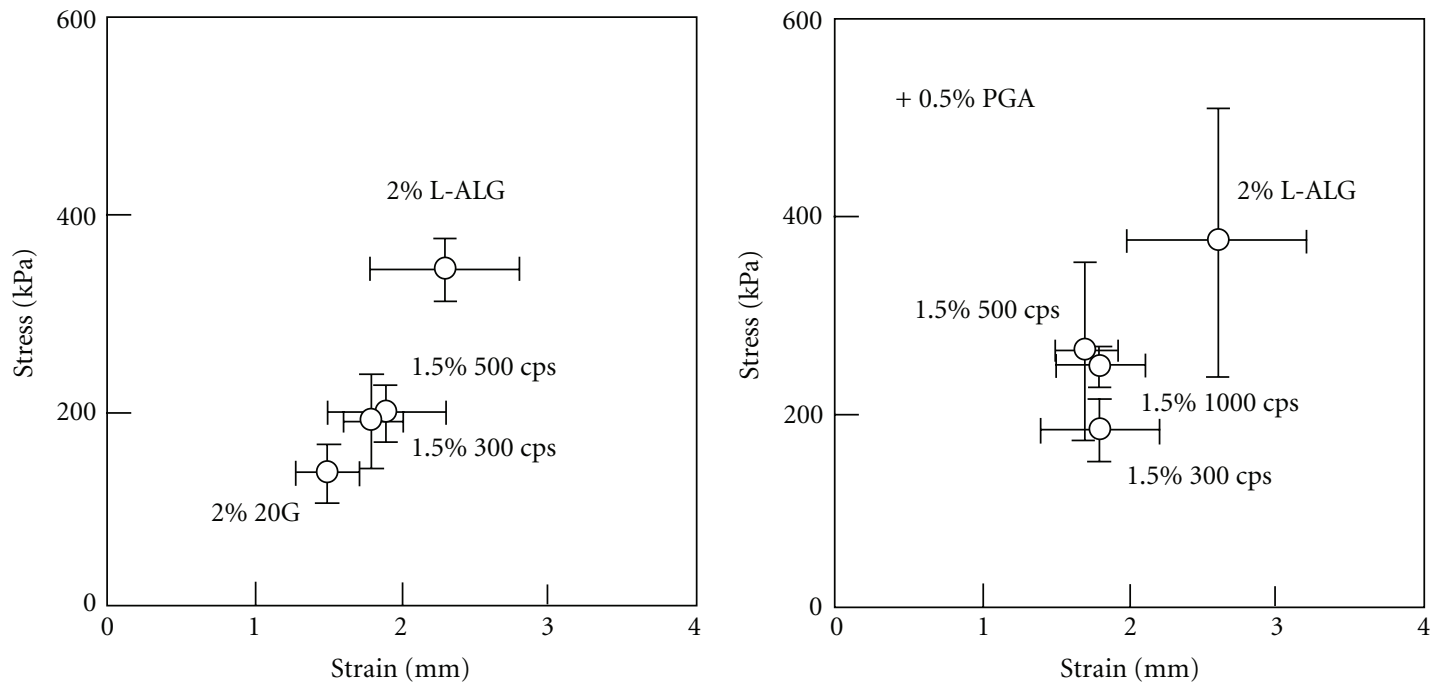

FIGURE 2: Rheological properties of alginate films containing AP $(n=3)$.

(Kyoto, Japan). Low-molecular-weight alginate (L-ALG) was obtained from Alfa Aesar (Ward Hill, MA, USA). Guluronicacid-rich alginate $(20 \mathrm{G})$ was supplied by the Kibun Food Chemifa Co. (Tokyo, Japan). PUL was supplied by the Hayashibara Biochemical Laboratories (Okayama, Japan). Polygalacturonic acid (PGA) was purchased from the MP Biomedicals (Solon, OH, USA). AP was purchased from the Wako Pure Chemicals (Osaka, Japan). All other chemicals were of reagent grade.

2.2. FD Preparation. Polysaccharides were dissolved in deionized water with agitation, and $1.5-4 \%(\mathrm{~W} / \mathrm{W})$ solutions were prepared. AP $(10 \mathrm{mg})$ was added to $10 \mathrm{~g}$ of the film base solutions, followed by thorough mixing, and $3.0 \mathrm{~g}$ of each solution was poured into a plastic Petri dish (diameter, $54 \mathrm{~mm}$ ). After $24 \mathrm{~h}$ at $37^{\circ} \mathrm{C}$, the circular films formed on the dish were transferred to a desiccator. Film formation was judged to have failed if a film could not be removed from the bottom of the dish. Film surfaces were observed with a digital microscope (VHX-900; Keyence Co., Osaka, Japan).

2.3. Film Thickness and Rheological Properties. Film thickness was measured at 10 points on each film using a micrometer (CLM1-15QM; Mitutoyo, Kawasaki, Japan) with a set 

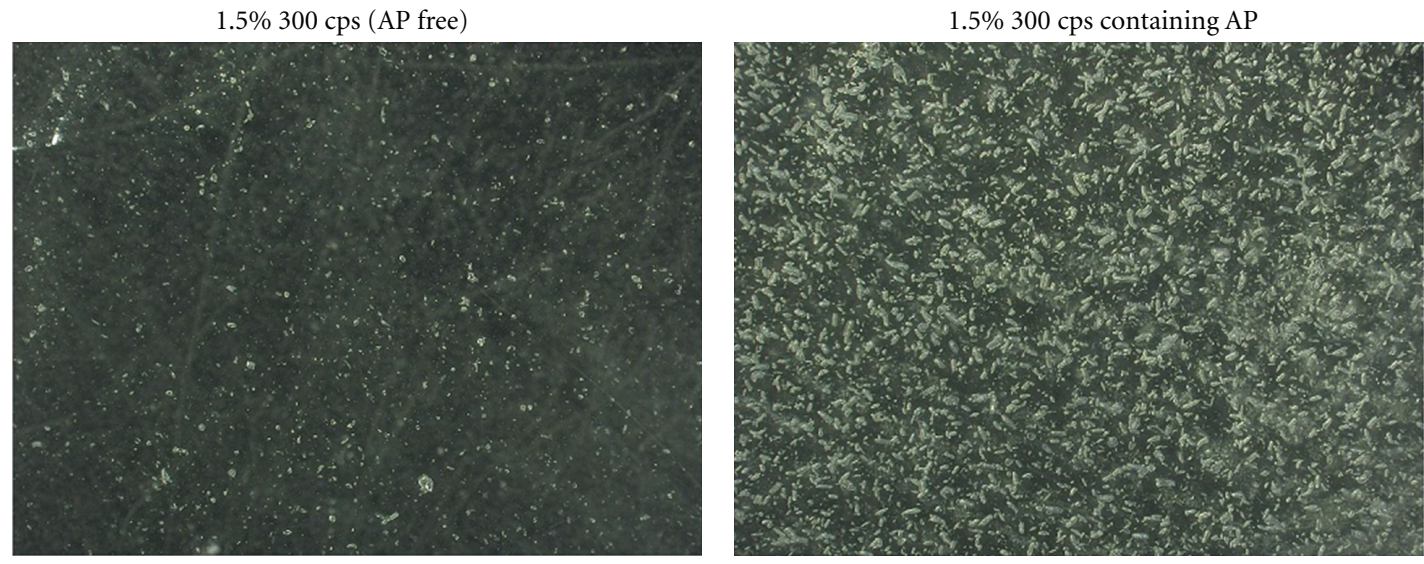

FIGURE 3: FD surface observed under digital microscope $(\times 50)$.

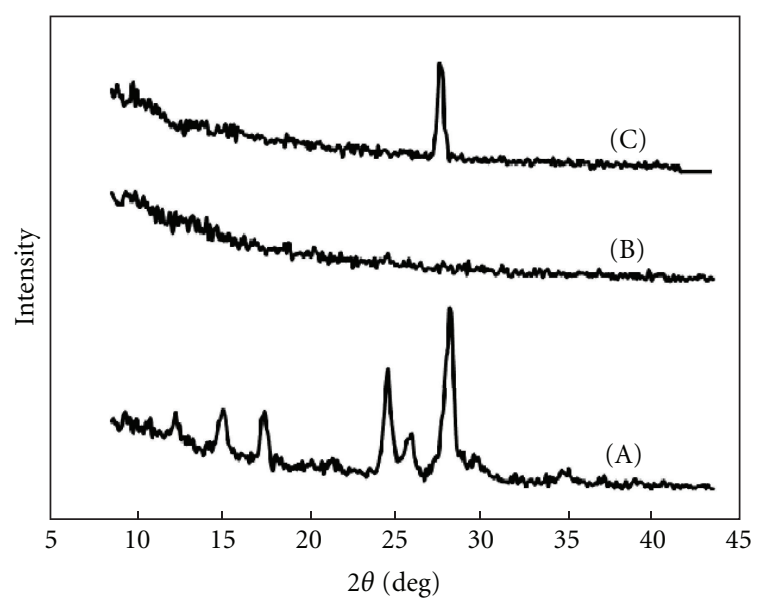

Figure 4: X-ray diffractograms. (A) AP (powder); (B) 1.5\% $300 \mathrm{cps}$ film (AP free); (C) 1.5\% $300 \mathrm{cps}$ film containing AP.

pressure of $0.5 \mathrm{~N}$. Measurements were made on 3 films, and the mean thickness was calculated for each type. The rheological properties of each film were determined using a rheometer (SUN RHEO TEX SD-700\#; Sun Scientific Co., Tokyo, Japan) at room temperature. The film was fixed on a vial (inner diameter, $1.4 \mathrm{~mm}$; outer diameter, $18.8 \mathrm{~mm}$ ) using joining tape (Scotch mending tape; Sumitomo $3 \mathrm{M}$ Ltd., Tokyo, Japan) and was probed with a cylindrical adapter (diameter, $5.0 \mathrm{~mm}$ ). Stress and strain were measured at the point at which the adapter broke through the film, and tests were performed in triplicate.

2.4. X-Ray Diffractometry. X-ray diffractometry was carried out using an automatic diffractometer (D8 DISCOVER with GADDS; Bruker AXS K.K., Yokohama, Japan) with a voltage of $40 \mathrm{kV}$ and a current of $40 \mathrm{~mA}$. The results of $\mathrm{X}$-ray diffraction were interpreted using computer software (Bruker AXS K.K.).

2.5. AP Dissolution Test. Physiological saline was used as the dissolution test medium. Films were placed in a plastic dish, and $10 \mathrm{~mL}$ of the dissolution medium preheated to
TABLE 1: Thickness of FDs containing AP.

\begin{tabular}{lc}
\hline Film base & Thickness $(\mu \mathrm{m}, n=3)$ \\
\hline $1.5 \% 300 \mathrm{cps}$ & $44 \pm 1$ \\
$1.5 \% 500 \mathrm{cps}$ & $55 \pm 9$ \\
$1.5 \% 300 \mathrm{cps}+0.5 \%$ PGA & $50 \pm 3$ \\
$1.5 \% 500 \mathrm{cps}+0.5 \%$ PGA & $65 \pm 12$ \\
$1.5 \% 1000 \mathrm{cps}+0.5 \%$ PGA & $48 \pm 6$ \\
\hline
\end{tabular}

$37^{\circ} \mathrm{C}$ was added. The dish was shaken at $300 \mathrm{rpm}$ in a shaker incubator (SI-300; As One Co., Osaka, Japan) at $37^{\circ} \mathrm{C}$. After $1,3,5,10,15,20,30,45$, and 60 minutes, $80 \mu \mathrm{L}$ aliquots were removed and placed into micro-test tubes $(1.5 \mathrm{~mL})$, and $720 \mu \mathrm{L}$ of methanol was added to precipitate the polysaccharide dissolved from the FD. Samples were mixed and centrifuged $(7,700 \times$ g, 5 min; H-1300; Kokusan Co., Saitama, Japan), and the supernatants were injected into an HPLC column. All tests were performed in triplicate. The HPLC system comprised an LC-6A pump (Shimadzu Co., Kyoto, Japan), a packed column $(150 \mathrm{~mm} \times 4.6 \mathrm{~mm}$, COSMOSIL 5C 18 -MS-II, Nacalai Tesque), and a SPD-6A UV detector (Shimadzu Co.). HPLC for the determination of $\mathrm{AP}$ was conducted at ambient temperature using $20 \mathrm{mM}$ acetate buffer $(\mathrm{pH} 4.5)$ at a flow rate of $1.0 \mathrm{~mL} / \mathrm{min}$ [14]. The detector wavelength was set at $254 \mathrm{~nm}$.

\section{Results and Discussion}

Using the casting method, $1.5-2 \%$ ALG or $4 \%$ PUL was poured into molds and the solvent was evaporated from the solution. The polysaccharides used in this study form circular films when the solution does not contain AP. In the presence of AP ( $1 \mathrm{mg} / \mathrm{g})$, both $300 \mathrm{cps}$ and $500 \mathrm{cps}$ formed circular films, but $1000 \mathrm{cps}$ and PUL did not form films, as shown in Figure 1. On the other hand, all of the polysaccharides were able to form films with the addition of $0.5 \%$ PGA to the film base solution, although cracks were observed in the case of films prepared with 4\% PUL and 0.5\% PGA. The thicknesses of FDs prepared with ALGs were $44-65 \mu \mathrm{m}$, as shown in Table 1. L-ALG (2\%) and 20 G (2\%) also formed 

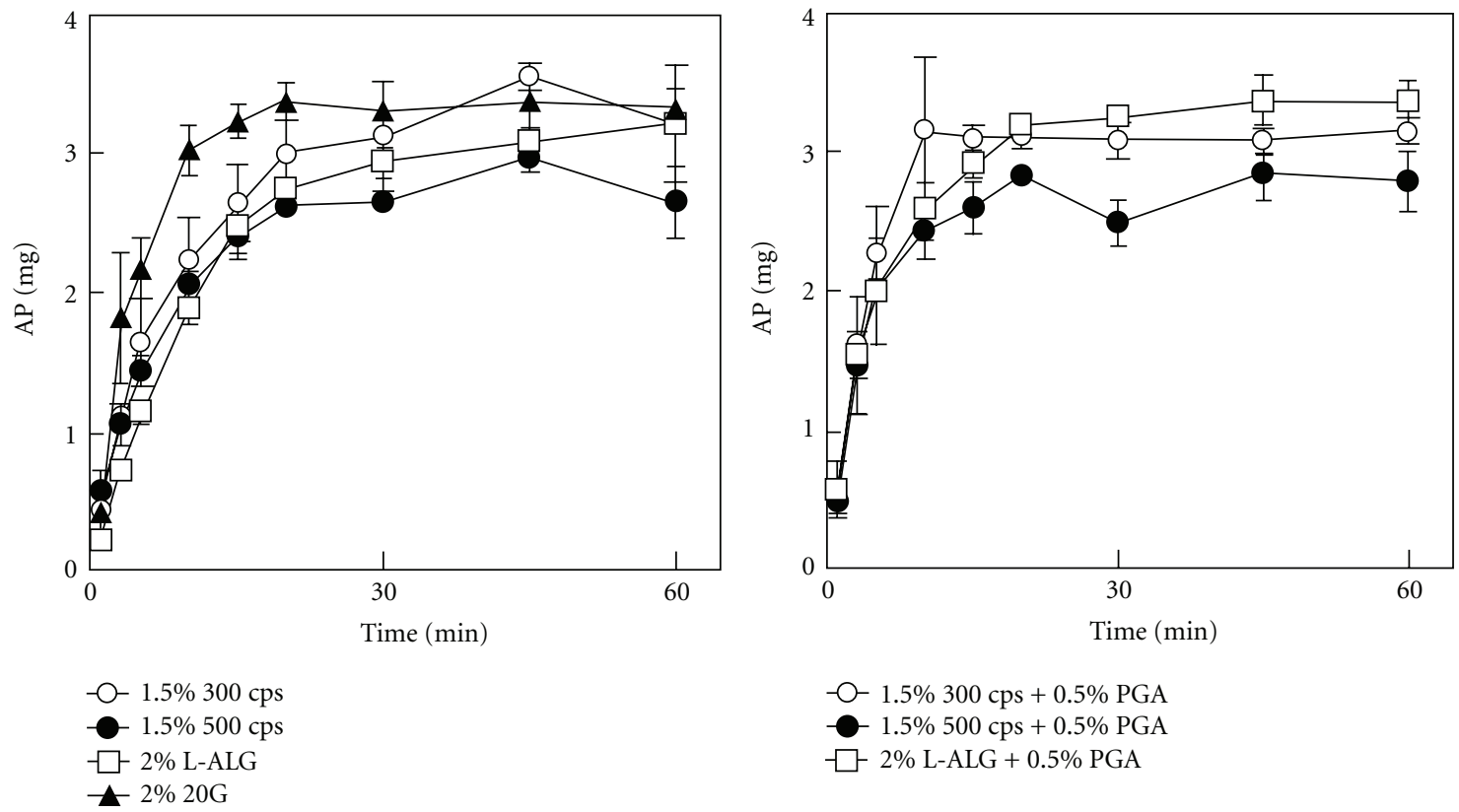

FIGURE 5: Release profiles of AP from FDs in physiological saline $(n=3)$.

films, and the thicknesses were $48 \pm 3 \mu \mathrm{m}$ and $37 \pm 2 \mu \mathrm{m}$, respectively. These results indicate that ALG is useful as a film base to prepare FDs incorporating AP.

FDs containing AP are applied to the oral cavity; therefore, they must be easy to handle. Figure 2 shows the rheological properties of FDs prepared with ALGs. All films were easy to handle and resistant to tearing, although $\mathrm{FD}$ properties varied with ALG species. Adding 0.5\% PGA to the film base solution did not affect FD strength, and no apparent relationship between film thickness and hardness was observed.

AP is dissolved in the polysaccharide solution, and the drug is incorporated into the matrix gradually formed by the polymer base. As shown in Figure 3, AP is homogenously present throughout the film. Therefore, AP would be distributed across the region to which FD is applied in the oral cavity.

Figure 4 shows the X-ray diffraction patterns for AP powder and FDs prepared with $1.5 \% 300 \mathrm{cps}$. AP exhibited a characteristic crystalline compound diffraction pattern. On the other hand, the diffraction pattern of FD was similar to that of an amorphous polymer, and FD containing AP showed a different pattern than AP powder. These results indicate that the crystal form of AP is only slightly present in FDs.

In the treatment of mucositis, solutions or suspensions of AP are administered in the oral cavity to act directly at the inflammation site. Therefore, AP needs to be released immediately upon contact with saliva, which is secreted from the salivary glands at $1.5-2.0 \mathrm{~mL} / \mathrm{min}$ after stimulation [15]. In this study, films were soaked in $10 \mathrm{~mL}$ of physiological saline, and the amount of AP released from the FDs was measured. In all FDs prepared with ALG, rapid swelling in the dissolution medium was observed with the naked eye, and the film itself dissolved in the medium within 20-30 min. As shown in Figure 5, incorporated AP was immediately released, irrespective of the ALG species used as a film base. In particular, all of the AP was released within $10 \mathrm{~min}$ from the FD prepared with $2 \% 20$ G. Similar AP release profiles were obtained with FDs containing PGA. However, the preparation did not dissolve in physiological saline, and film residue remained at the end of the dissolution test. These results show that AP is present in the polymer matrix and is released through pores formed by permeation of the dissolution medium.

\section{Conclusions}

FDs allow the distribution of a drug across the region to which the FD is attached. In this study, FDs were prepared using natural polysaccharides without addition of plasticizers or dissolution into organic solvents. FDs prepared with ALG are able to incorporate AP and immediately release the drug in limited dissolution medium. FDs are thus useful for preventing or treating localized problems in the oral cavity, such as mucositis. They also simplify the administration of drugs to patients.

\section{Acknowledgment}

The authors would like to thank Dr. M Kimizu (Industrial Research Institute of Ishikawa) for his help and advice with regard to X-ray diffractometry.

\section{References}

[1] H. V. Worthington, J. E. Clarkson, G. Bryan et al., "Interventions for preventing oral mucositis for patients with cancer 
receiving treatment," Cochrane Database of Systematic Reviews, vol. 12, p. CD000978, 2010.

[2] D. M. Keefe, M. M. Schubert, L. S. Elting et al., "Updated clinical practice guidelines for the prevention and treatment of mucositis," Cancer, vol. 109, no. 5, pp. 820-831, 2007.

[3] R. V. Lalla, M. M. Schubert, R. J. Bensadoun, and D. Keefe, "Anti-inflammatory agents in the management of alimentary mucositis," Supportive Care in Cancer, vol. 14, no. 6, pp. 558$565,2006$.

[4] H. Dozono, M. Murakami, T. Watanabe et al., "The prevention of stomatitis induced by anti-cancer drugs," Japanese Journal of Cancer and Chemotherapy, vol. 17, no. 4 Pt 2, pp. 931-933, 1990.

[5] S. Nalamachu, D. Hassman, M. S. Wallace, S. Dumble, R. Derrick, and J. Howell, "Long-term effectiveness and tolerability of sublingual fentanyl orally disintegrating tablet for the treatment of breakthrough cancer pain," Current Medical Research and Opinion, vol. 27, no. 3, pp. 519-530, 2011.

[6] F. A. Alhusban, A. M. El-Shaer, R. J. Jones, and A. R. Mohammed, "Recent patents and trends in orally disintegrating tablets," Recent Patents on Drug Delivery and Formulation, vol. 4, no. 3, pp. 178-197, 2010.

[7] F. Cilurzo, I. E. Cupone, P. Minghetti, S. Buratti, C. G.M. Gennari, and L. Montanari, "Diclofenac fast-dissolving film: suppression of bitterness by a taste-sensing system," Drug Development and Industrial Pharmacy, vol. 37, no. 3, pp. 252259, 2011.

[8] F. Cilurzo, I. E. Cupone, P. Minghetti et al., "Nicotine fast dissolving films made of maltodextrins: a feasibility study," AAPS PharmSciTech, vol. 11, no. 14, pp. 1511-1517, 2010.

[9] H. Shimoda, K. Taniguchi, M. Nishimura et al., "Preparation of a fast dissolving oral thin film containing dexamethasone: a possible application to antiemesis during cancer chemotherapy," European Journal of Pharmaceutics and Biopharmaceutics, vol. 73, no. 3, pp. 361-365, 2009.

[10] V. Garsuch and J. Breitkreutz, "Comparative investigations on different polymers for the preparation of fast-dissolving oral films," Journal of Pharmacy and Pharmacology, vol. 62, no. 4, pp. 539-545, 2010.

[11] Y. Sakuda, A. Ito, M. Sasatsu, and Y. Machida, "Preparation and evaluation of medicinal carbon oral films," Chemical and Pharmaceutical Bulletin, vol. 58, no. 4, pp. 454-457, 2010.

[12] Y. Murata, T. Isobe, K. Kofuji, N. Nishida, and R. Kamaguchi, "Preparation of fast dissolving films for oral dosage from natural polysaccharides," Materials, vol. 3, pp. 4291-4299, 2010.

[13] Y. Sakata and M. Otsuka, "Evaluation of relationship between molecular behaviour and mechanical strength of pullulan films," International Journal of Pharmaceutics, vol. 374, no. 1-2, pp. 33-38, 2009.

[14] M. K. Reinders, L. C. Nijdam, E. N. van Roon et al., "A simple method for quantification of allopurinol and oxipurinol in human serum by high-performance liquid chromatography with UV-detection," Journal of Pharmaceutical and Biomedical Analysis, vol. 45, no. 2, pp. 312-317, 2007.

[15] B. Nauntofte, J. O. Tenovuo, and F. Lagerlof, "Secretion and composition of saliva," in Dental Caries the Disease and Its Clinical Management, O. Fejerskov and E. A. M. Kidd, Eds., pp. 7-27, Blackwell Munksgaad, Oxford, UK, 2003. 

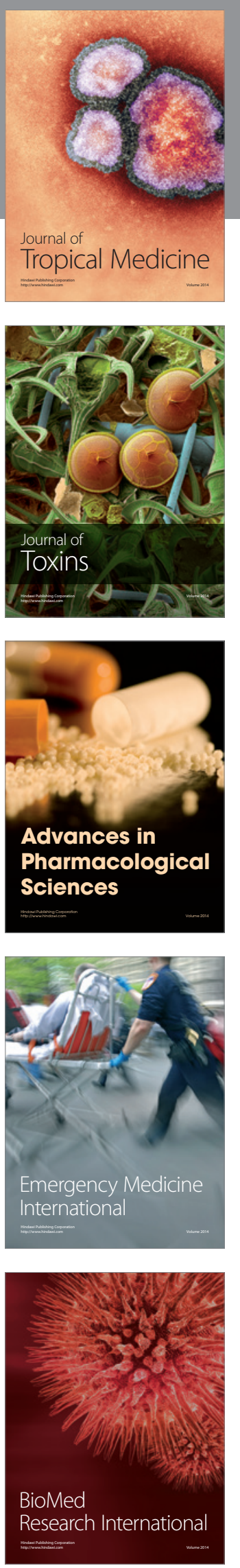
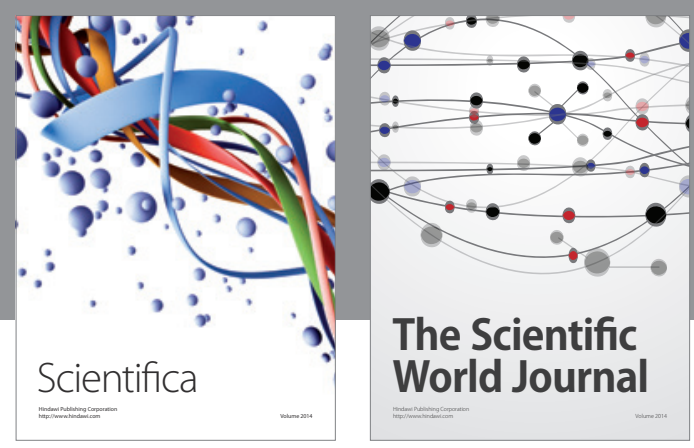

The Scientific World Journal
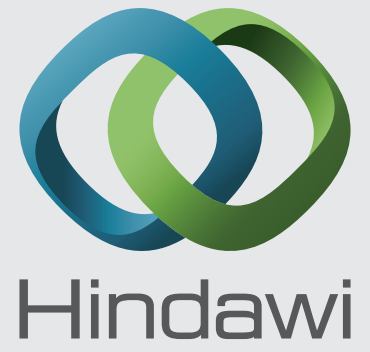

Submit your manuscripts at

http://www.hindawi.com
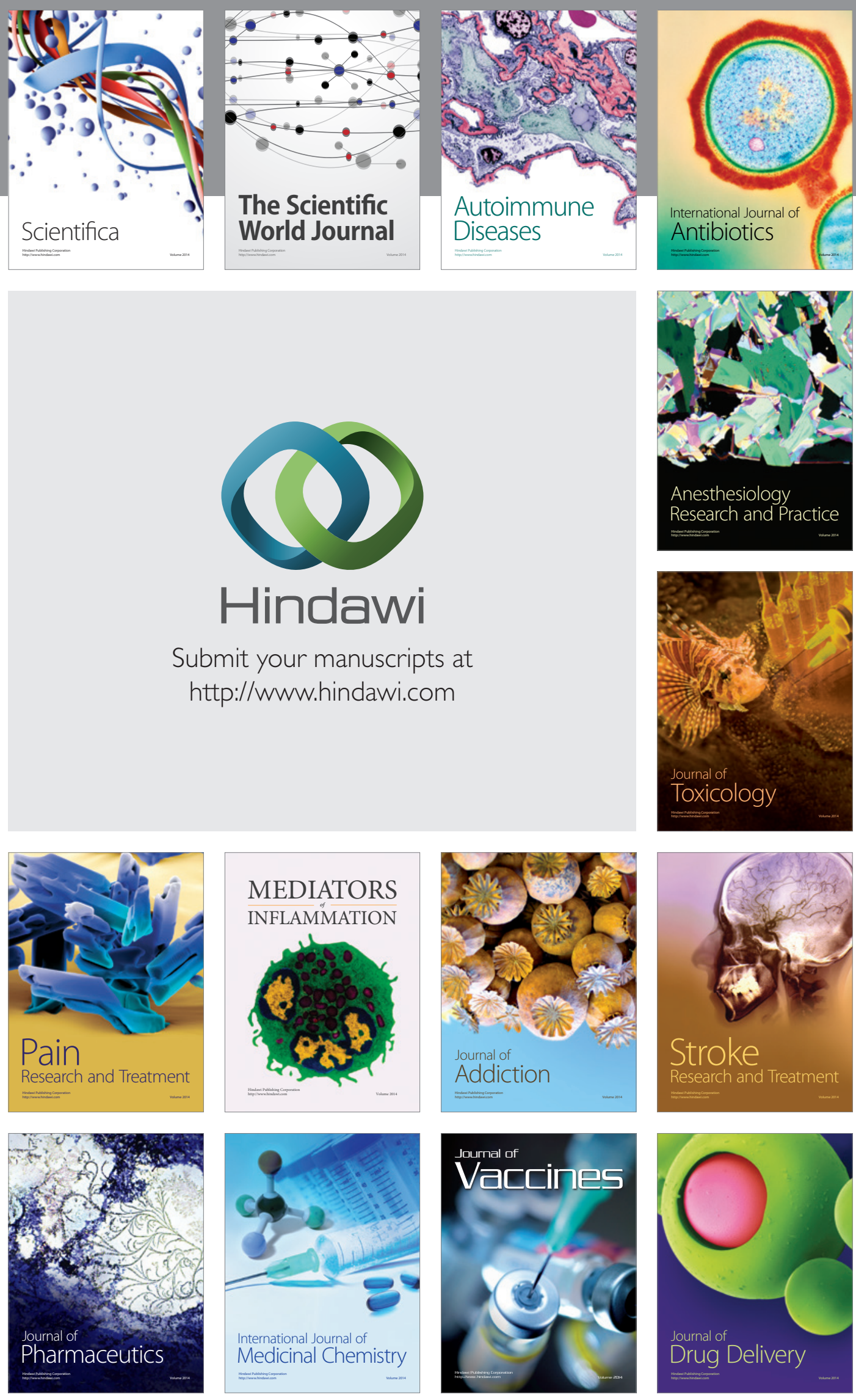